\title{
Psychosocial maturity and the forming of impressions
}

\author{
JEFFREY A. GOLDMAN \\ Hartwick College, Oneonta, New York 13820 \\ and \\ PAUL V. OLCZAK \\ State University of New York, Geneseo, New York 14454
}

\begin{abstract}
Erikson's concept of psychosocial maturity (PSM), assessed by scores on the Inventory of Psychosocial Development, was related to interpersonal behavior in a person perception experiment. This personality variable was found to moderate ratings of others in the standard impression-formation paradigm. Results indicated that high-PSM individuals were more extreme in their responses to social stimuli than were low-PSM individuals, but only for the middle-ranged stimuli. The results were discussed in terms of the potential mechanisms by which PSM affects the forming of impressions.
\end{abstract}

Based upon Erikson's first six developmental stages (trust vs. mistrust, autonomy vs. shame and doubt, initiative vs. guilt, industry vs. inferiority, identity vs. role confusion, and intimacy vs. isolation), Constantinople (1969) developed a personality questionnaire, the Inventory of Psychosocial Development (IPD). A measure of one's overall level of psychosocial maturity (PSM) has recently been utilized by summing the scores of these separate stages. Strong validity data for this instrument, though, are lacking, with no validity estimates having been made for the subscales (Constantinople, 1969). Existing research, however, seems encouraging (Goldman \& Olczak, 1976; Olczak \& Goldman, 1975; Reimanis, 1974; Waterman, 1972).

The present experiment looks at the relationship between PSM and cognitive processing in social judgment in an attempt to determine how PSM actually affects interpersonal cognition.

Cognitive processing in the formation of impressions of others may be considered as a task of integrating information about the other with one's dispositional biases toward others (Anderson, 1974). A piece of information may be represented by a scale value, referring to its position on the response dimension and weight, or importance for the judgment. In many instances, the integration may be represented as a weighted average of information about the other and the value of the disposition bias, as in Equation 1:

$$
R=\frac{k w A s_{i}}{k w_{i}+\left(1-w_{i}\right)}+\frac{\left(1-w_{i}\right) s_{o}}{k w+\left(1-w_{i}\right)}
$$

The authors wish to thank Dr. Martin F. Kaplan for his helpful comments during the preparation of this manuscript. Requests for reprints should be sent to Dr. Jeffrey A. Goldman, Psychology Department, Hartwick College, Oneonta, New York 13820. where $R$ is the person impression, $k$ is the size of the set of information, $s_{i}$ is the scale value of adjective $i, s_{o}$ is the initial or a priori impression, and $w_{i}$ is the weight associated with adjective $\mathrm{i}$. In Equation 1, the $\mathrm{k}$ stimuli are constrained to have the same scale value, $\dot{s}_{i}$, and the same weight, $w_{i}$, and the weight of initial impression and stimuli are assumed to sum to unity so that $s_{i}$ and $s_{o}$ are averaged. A more general averaging model can be applied to instances where the stimuli in a set are not equal in value or weight, but we need not be concerned with such a model in the study reported here.

As Kaplan (1975) points out, individual personality effects may be found at several points in the integration process. Personality factors have been shown to affect the weighting of stimulus components, the value the subject may assign to stimulus components, or the preexisting dispositions they bring to the judgment situation. For instance, with respect to judgments on whom to date, individuals may differ on how much they value another's dress $\left(s_{i}\right)$, on how much emphasis they place on it $\left(\mathrm{w}_{\mathrm{i}}\right)$, or on their preexisting dispositions to dating in general $\left(s_{o}\right)$. If the weight $\left(w_{i}\right)$ parameter is affected, increasing the set size yields diverging curves due to the multiplicative relation between $\mathrm{k}$ and $\mathrm{w}$. If scale value $\left(s_{i}\right)$ is affected, the effects of individual difference are the same as $w$, while differences in the preexisting impression yield converging curves as set size increases.

A possible interpretation of PSM's effect on the impression-formation response stems from White's (1960) expansion of Erikson's notions. White states that high-PSM individuals possess a greater degree of competence than do low-PSM individuals. Their greater sense of competence is the result of activities generated by an effectance motive.

If high-PSM individuals have more effectance motivation, as suggested by White (1960), social stimuli should 
be more salient for them, in contrast to low-PSM individuals. If so, then high-PSM individuals should place more weight on information and, consequently, have more extreme responding in impression formation (where $s_{i}<s_{o}<s_{i}$ ). In fact, in the attraction paradigm high-PSM subjects are more polar in their responses to strangers of varying degrees of attitude similarity than are low-PSM subjects (Goldman \& Olczak, 1976). If the interpersonal attraction and impression-formation areas of human judgment are as similar as some suggest (i.e., Kaplan \& Anderson, 1973), then PSM should have a similar moderating role in both paradigms. Another possibility is that high-PSM subjects, being more mature, are more objective, that is, attuned to external rather than internal stimuli, and thus place greater emphasis on weight or scale value and less on the initial impression compared to low-PSM subjects. Consequently, using either analysis, it is predicted that extremization of impression-formation responding will occur for highPSM subjects when compared to their low-PSM counterparts.

\section{METHOD}

\section{Subjects}

Eighty undergraduates (40 male and 40 female) at Hartwick College were drawn from the upper and lower quartiles of an initial pool of 389 subjects who had completed the measure of PSM some weeks prior to the experiment.

\section{Measure of Psychosocial Maturity}

The Inventory of Psychosocial Development (IPD) developed by Constantinople (1969) was used. The IPD consists of 60 rating scale items, 5 reflecting successful and 5 reflecting unsuccessful resolutions of each of Erikson's first six stages of psychosocial development. Short words or phrases, rated on a 7point scale, describe how characteristic (7) or uncharacteristic (1) that phrase is of the rater. Six separate subscales were derived based upon Erikson's first six stages of psychosocial development. For each subscale the ratings on the five items reflecting successful resolution are summed and then added to the reversed scores for the five items reflecting unsuccessful resolution. For example, an item contributing to the measure on Erikson's first stage (trust vs. mistrust) reflecting unsuccessful resolution (e.g., "pessimistic, little hope") with a score of 7 (i.e., extremely characteristic) is reversed to a score of 1 and added to those items keyed in the positive direction. This procedure yields a potential range of scores for each subscale from 10 to 70 . Scores on each of the six subscales (trust vs. mistrust, autonomy vs. shame and doubt, initiative vs. guilt, industry vs. inferiority, identity vs. role confusion, and intimacy vs. isolation) are then added to derive an overall measure of PSM (scores ranging from 60 to 420 ).
Criteria for selection in the present study were an IPD score of below 285 for low-PSM and an IPD score greater than 310 for high-PSM subjects. The mean scores for the experimental groups were 260.2 for low-PSM subjects and 328.8 for high-PSM subjects. The means of the actual groups used in the present study are located fairly close together given the potential range of the scale. Presently, norms for the total PSM score do not exist, and the present sample may be skewed in the direction of high PSM.

\section{Procedure}

The procedure was essentially a replication of Anderson's (1967) study, with the addition of PSM as a between-subjects factor. Each subject received a set of adjectives and was told that each adjective was supplied by a different acquaintance of the stimulus person. Each subject was then asked to rate the person described by each set on a rating scale of -10 to +10 , with -10 anchored at "dislike very much" and +10 anchored at "like very much." Scores were then converted to a 0-20 scale to simplify analysis.

Experimental sets were constructed by combining highly favorable $(\mathrm{H})$, moderately favorable $(\mathrm{M}+)$, moderately unfavorable (M-), or highly unfavorable (L) adjectives into sets of one, three, and six stimuli. The specific $H$ and $L$ adjectives used were identical to those reported by Anderson (1967), favorability being determined by mean ratings in a normative sample (Anderson, 1968). The specific $M+$ and $M-$ adjectives used were randomly drawn from $M+$ and $M-$ sublists (Anderson, 1968). The two sublists used were: $M+$ from 3.45 (painstaking) to 3.74 (persuasive) and $M-$ from 2.22 (unpopular) to 2.54 (dependent). Sets consisted of $\mathrm{H}, \mathrm{M}+, \mathrm{M}-, \mathrm{L}, \mathrm{HHH}, \mathrm{M}+\mathrm{M}+\mathrm{M}+$, M-M-M-, LLL, HHHHHH, $\mathbf{M}+\mathbf{M}+\mathbf{M}+\mathbf{M}+\mathbf{M}+\mathbf{M}+, \mathbf{M}-\mathbf{M}-\mathbf{M}-$ $\mathbf{M}-\mathbf{M}-\mathbf{M}-$, and LLLLLL. Thus, there were four main subgroups of trait sets corresponding to favorability, with six replications of Set Size 1 within each subgroup, two of Set Size 3, and one of Size 6. This procedure was repeated for a second series of six $\mathrm{H}, \mathrm{M}+, \mathrm{M}-$, and $\mathrm{L}$ adjectives, yielding a total of 72 sets. In addition, 12 practice sets of mixed favorability and set size were included. Each set was typed on a card for simultaneous presentation, vertical order of adjectives being determined randomly and all sets ordered randomly for each subject.

\section{Design}

A 2 by 3 by 4 factorial was used, with PSM as a betweensubjects factor (high PSM vs. low PSM) and set size $(1,3,6)$ and trait favorability within sets $(\mathrm{H}, \mathrm{M}+, \mathrm{M}-, \mathrm{L})$ as withinsubjects factors.

\section{RESULTS}

The mean likability ratings as a function of degree of judge's PSM, favorability, and set size are presented in Table 1.

Data were analyzed by means of a one betweensubjects and two within-subjects factor analysis of variance. For the between-subjects comparisons the effect of PSM was not significant $(F<1.0)$. For the

Table 1

Mean Likability Ratings as a Function of a Judge's Degree of Psychosocial Maturity, Favorability, and Set Size

Likability

\begin{tabular}{|c|c|c|c|c|c|c|c|c|c|c|c|c|}
\hline \multirow{3}{*}{$\begin{array}{c}\text { Degree of } \\
\text { Judge's PSM }\end{array}$} & \multicolumn{3}{|c|}{$\mathrm{L}$} & \multicolumn{3}{|c|}{ M- } & \multicolumn{3}{|c|}{$\mathrm{M}+$} & \multicolumn{3}{|c|}{$\mathrm{H}$} \\
\hline & \multicolumn{3}{|c|}{ Set Size } & \multicolumn{3}{|c|}{ Set Size } & \multicolumn{3}{|c|}{ Set Size } & \multicolumn{3}{|c|}{ Set Size } \\
\hline & 1 & 3 & 6 & 1 & 3 & 6 & 1 & 3 & 6 & 1 & 3 & 6 \\
\hline High & 5.0 & 3.2 & 2.0 & 10.0 & 8.7 & 7.2 & 11.8 & 12.1 & 13.4 & 15.4 & 16.5 & 17.8 \\
\hline Low & 5.3 & 3.4 & 2.0 & 10.2 & 9.0 & 8.8 & 11.6 & 12.0 & 12.2 & 15.5 & 16.4 & 17.6 \\
\hline
\end{tabular}


within-subjects comparisons, the effects of favorability, set size, favorability by set size, and the PSM by Favorability by Set Size interaction were significant $[\mathrm{Fs}(3 / 234$, $2 / 156,6 / 468,6 / 468)=746.9,14.4,72.1,3.8, \mathrm{ps}<.01$ for each]. The first interaction reflects the frequently noted set size effect or tendency for responses to become more polarized with increased amounts of information (Anderson, 1967). Newman-Keuls comparisons on the triple interaction indicated that on $6 \mathrm{M}$ - valued adjectives high-PSM subjects rated stimulus persons significantly lower than did low-PSM subjects $(\mathrm{p}<.05)$; on $6 \mathrm{M}+$ valued adjectives high-PSM subjects rated stimulus persons significantly higher than did lowPSM subjects $(\mathrm{p}<.05)$.

\section{DISCUSSION}

The present interaction partially agrees with the prediction. It appears that high-PSM individuals are more affected by social stimuli, and their responses are consequently more extreme under certain conditions.

High-PSM subjects were more extreme than low-PSM subjects in their responses to six adjective trait descriptions of another person only when stimuli were moderately polarized. This is somewhat similar to the moderating effect that PSM has on interpersonal attraction (Goldman \& Olczak, 1976), where high-PSM subjects rated the stranger significantly higher in attraction at high levels of similarity and significantly lower at low levels of similarity when compared to low-PSM individuals.

A possible explanation for the present finding is that $w_{i}$ (or $s_{\mathbf{i}}$ ) is greater for high-PSM subjects. Increasing the amount of $\mathrm{k}$ would then be multiplying higher $\mathrm{w}_{\mathrm{i}}\left(\right.$ or $\mathrm{s}_{\mathrm{i}}$ ), thus increasing the effect of $k$. Thus, set size effects should be greater for highPSM individulas. The fact that no personality differences were found in responding to $\mathrm{H}$ or $\mathrm{L}$ adjectives is not surprising. As Johnson, Gormly, and Curran (Note 1) point out, the use of middle-range stimuli better allows for the expression of individual differences when compared to extreme stimuli. However, it is somewhat puzzling at this stage that this finding occurred only for $6 \mathrm{M}+$ and $6 \mathrm{M}-$ adjectives.

Whether the present findings are due to differences in scale values $\left(s_{\mathbf{i}}\right)$ or weighting $\left(w_{\mathbf{j}}\right)$ remains, however, unknown. To separate the effects of differential evaluation of traits from the effects of differential weighting, future research should have each subject preselect his/her own scale values to constitute homogeneous groups of adjectives.

Rather than influencing the impact the stimuli have, PSM may also affect a subject's self-confidence or willingness to make unambiguous judgments of a stimulus person, independent of weighting of stimulus information relative to $s_{\mathrm{o}}$. Whereas the weight assigned to stimuli enters into the model equation and reflects a true subjective judgment factor, the weight assigned to the response which reflects a response scale usage factor does not enter into the model equation. To rule out this alternative to the salience explanation, future research should obtain from highand low-PSM subjects ratings of their confidence in judging strangers. Since the results of the present experiment (the extremity effects) may be due to the aforementioned possibility that PSM individuals generally tend to make more extreme responses, future research should also assess PSM's role in making choices in a paired-comparisons paradigm where one chooses between two individuals, each described by a different set of adjectives (Levin \& Schmidt, 1970; Schmidt \& Levin, 1972). In this type of task, one's tendency to use extreme scale categories is detectable.

\section{REFERENCE NOTE}

1. Johnson, C. D., Gormly, J. P., \& Curran, J. P. Social desirability anxiety and interpersonal disagreements among females. Paper presented at the 1974 convention of the Midwestern Psychological Association, Chicago, Illinois, 1974.

\section{REFERENCES}

Anderson, N. H. Averaging model analysis of set-size effect in impression formation. Journal of Experimental Psychology, 1967, 75, 158-165.

ANDERSON, N. H. Likableness ratings of 555 personality-trait words. Journal of Personality and Social Psychology, 1968, 9, 272-279.

ANDERSON, N. H. Information integration theory: A brief survey. In D. H. Krantz, R. D. Atkinson, R. D. Luce, \& P. Suppes (Eds.), Contemporary developments in mathematical psychology (Vol. 2). San Francisco: W. H. Freeman, 1974.

Constantinople, A. An Eriksonian measure of personality development in college students. Developmental Psychology, 1969, 1, 357-372.

Goldman, J. A., \& Olczak, P. V. Psychosocial maturity and interpersonal attraction. Journal of Research in Personality, 1976, 10, 146-154.

KAPLAN, M. F. Information integration in social judgment: Interaction of judge and informational components. In $\mathbf{M}$. Kaplan \& S. Schwartz (Eds.), Human judgment and decision processes. New York: Academic Press, 1975.

KAPLAN, M. F., \& ANDERSON, N. H. Information integration theory and reinforcement theory as approaches to interpersonal attraction. Journal of Personality and Social Psychology, 1973, 28, 301-312.

LEvin, I. P., \& SchmidT, C. F. A paired-comparisons paradigm for investigating person perceptions. Psychonomic Science, 1970, 20, 359-361.

Olczak, P. V., \& Goldman, J. A. The relationship between self-actualization and psychosocial maturity. Journal of Clinical Psychology, 1975, 31, 415-419.

Reimanis, G. Psychosocial development, anomie and mood. Journal of Personality and Social Psychology, 1974, 29, 355-357.

Schmidt, C. F., \& Levin, I. P. Test of an averaging model of person preference: Effert of context. Journal of Personality and Social Psychology, 1972, 23, 277-282.

WATERman, A. S. Relationship between the psychosocial maturity of entering college freshmen and their expectations about college. Journal of Counseling Psychology, 1972, 19, 42-46.

White, R. W. Competence and the psychosexual stages of development. In M. R. Jones (Ed.), Nebraska Symposium on Motivation. Lincoln: University of Nebraska Press, 1960. Pp. 97-140.

(Received for publication February 24, 1978.) 